\title{
Method
}

\section{Single-Tube Multiplex Polymerase Chain Reaction for the Detection of Genes Encoding Enterobacteriaceae Carbapenemase}

\begin{abstract}
Masanori Watahiki ${ }^{1 *}$, Ryuji Kawahara $^{2}$, Masahiro Suzuki ${ }^{3 * *}$, Miyako Aoki ${ }^{3}$, Kaoru Uchida ${ }^{1}$, Yuko Matsumoto $^{4}$, Yuko Kumagai ${ }^{5}$, Makiko Noda ${ }^{6}$, Kanako Masuda ${ }^{7}$, Chiemi Fukuda ${ }^{8}$, Seiya Harada ${ }^{9}$, Keiko Senba $^{10}$, Masato Suzuki ${ }^{11}$, Mari Matsui ${ }^{11}$, Satowa Suzuki ${ }^{11}$, Keigo Shibayama ${ }^{12}$, and Hiroto Shinomiya ${ }^{10}$

${ }^{1}$ Department of Bacteriology, Toyama Institute of Health, Toyama ${ }^{2}$ Division of Microbiology, Osaka Institute of Public Health, Osaka; ${ }^{3}$ Department of Microbiology and Medical Zoology, Aichi Prefectural Institute of Public Health, Aichi; ${ }^{4}$ Microbiological Testing and Research Division, Yokohama City Institute of Public Health, Kanagawa; ${ }^{5}$ Hygiene Division, Bacteriology Section, Akita Prefectural Research Center for Public Health and Environment, Akita; ${ }^{6}$ Department of Infectious Diseases, Gifu Prefectural Research Institute for Health and Environmental Sciences, Gifu; ${ }^{7}$ Hiroshima Prefectural Technology Research Institute, Public Health and Environment Center, Hiroshima: ${ }^{8}$ Department of Microbiology, Kagawa Prefectural Research Institute for Environmental Sciences and Public Health, Kagawa; ${ }^{9}$ Department of Microbiology, Kumamoto Prefectural Institute of Public Health and Environmental Science, Kumamoto; ${ }^{10}$ Department of Microbiology,

Ehime Prefectural Institute of Public Health and Environmental Science, Ehime; ${ }^{11}$ Antimicrobial Resistance Research Center, National Institute of Infectious Diseases, Tokyo; and ${ }^{12}$ Department of Bacteriology II, National Institute of Infectious Diseases, Tokyo, Japan
\end{abstract}

\begin{abstract}
SUMMARY: A multiplex PCR assay in a single tube was developed for the detection of the carbapenemase genes of Enterobacteriaceae. Primers were designed to amplify the following six carbapenemase genes: $b l a_{\mathrm{KPC}}, b l a_{\mathrm{IMP}}, b l a_{\mathrm{NDM}}, b l a_{\mathrm{VIM}}, b l a_{\mathrm{OXA}-48-\mathrm{like}}$, and $b l a_{\mathrm{GES}}$. Of $70 b a_{\mathrm{IMP}}$ variants, 67 subtypes were simulated to be PCR-positive based on in silico simulation and the primer-design strategy. After determining the optimal PCR conditions and performing in vitro assays, the performance of the PCR assay was evaluated using 51 and 91 clinical isolates with and without carbapenemase genes, respectively. In conclusion, the combination of multiplex PCR primers and QIAGEN Multiplex PCR Plus Kit was used to determine the best performance for the rapid and efficient screening of carbapenemase genes in Enterobacteriaceae. The assay had an overall sensitivity and specificity of $100 \%$. This PCR assay compensates for the limitations of phenotypic testing, such as antimicrobial susceptibility testing and the modified carbapenem inactivation method, in clinical and public health settings.
\end{abstract}

\section{INTRODUCTION}

Enterobacteriaceae are a large family of Gramnegative bacteria of non-spore forming facultative anaerobes that ferment sugars to produce lactic acid. Many of these family members are commonly found in the human gut flora, some are found in water or soil, and others as parasites in a variety of different animals and plants (1). Some of these bacteria are sources of community-acquired and nosocomial infections, with a propensity to spread easily between humans and to acquire genetic material through horizontal gene transfer, mediated by plasmids and transposons. $\beta$-lactam drugs

Received February 19, 2019. Accepted October 17, 2019.

J-STAGE Advance Publication November 29, 2019.

DOI: 10.7883/yoken.JJID.2019.041

*Corresponding author: Mailing address: Department of Bacteriology, Toyama Institute of Health, 17-1, Nakataikoyama, Imizu, Toyama 939-0363, Japan. Tel: +81766-56-8142, Fax: +81-766-56-7326. E-mail: masanori. watahiki01@pref.toyama.lg.jp

***Present Address: Department of Microbiology, School of Medicine, Fujita Health University, Aichi, Japan. are often considered the primary therapeutic agent for common infectious diseases; carbapenem antibiotics, in particular, are often considered as the last resort for treatment. In recent years, instances of carbapenemresistant Enterobacteriaceae (CRE) as causative agents of nosocomial infections have been increasing, creating difficulties for the treatment of disease. Therefore, the emergence and spread of CRE is a major concern in both clinical and public health settings $(2,3)$.

The central mechanism for carbapenem resistance is the production of $\beta$-lactamases, known as carbapenemases, which degrade carbapenem. Carbapenem-resistant bacteria that produce these enzymes are referred to as carbapenemase-producing Enterobacteriaceae (CPE). In general, $\beta$-lactamase is classified into four classes, from A to D, based on Ambler's classification (4). Among these, three classes show carbapenemase activity. Class A carbapenemases include KPC, SME, IMI, NMC-A, SFC, BIC, and several GES enzymes and are mainly produced by members of Enterobacteriaceae. Class $\mathrm{B}$ enzymes are metallo- $\beta$-lactamases (MBLs) that efficiently hydrolyze carbapenems and are inhibited by chelating agents, such as EDTA. They include the IMP, VIM, NDM, IND, DIM, GIM, CPH-A, KHM- 
1, and SMB enzymes. Important enzymes detected in Enterobacteriaceae include the IMP, VIM, and NDM families. Class D enzymes, known as oxacillinases with carbapenemase activity, are comprised of OXA-23like, OXA-24/40-like, OXA-48-like, OXA-51-like, and OXA-58-like families. Among these, the OXA-48-like enzymes with carbapenemase activity are encountered frequently in Enterobacteriaceae, whereas the others are mainly detected in glucose non-fermentative bacteria, such as Acinetobacter species (5). Such CPE often harbors plasmids encoding enzyme genes; the plasmid diffuses and spreads across bacterial species of Enterobacteriaceae very easily (5). Therefore, CPE are a significant concern in clinical and public health settings.

CRE that do not produce carbapenemase are also common. Such CREs include extended-spectrum $\beta$ lactamase (ESBL)- or AmpC $\beta$-lactamase-producing Enterobacteriaceae with plasmid-mediated (6) or chromosome-encoded (7) genes with porin mutations (8), resulting in a carbapenem-resistant phenotype. Such resistance to carbapenem is thought to be a low risk to public health because these carbapenem-resistant phenotypes do not transfer horizontally; however occasionally, outbreaks in hospital settings with the same strain may occur, such that it is necessary to monitor them in clinical settings (9).

CRE infectious diseases are increasing in the US and Europe, as many CRE harbor $\beta$-lactamase genes, such as $b l a_{\mathrm{KPC}}, b l a_{\mathrm{OXA}-48-\mathrm{like}}$, and $b l a_{\mathrm{NDM}}$. These carbapenemases have already spread internationally, but significant regional differences exist from a global perspective (2). Most CPEs detected in Japan produce IMPs, and in recent years, due to the globalization of human movement, pathogens have also spread globally in a short time. Therefore, as the number of visitors to Japan has increased, there are concerns that problematic resistant bacteria from overseas could infect the Japanese population. As a result, in 2014, infectious diseases caused by CRE were classified as notifiable diseases under infection control laws to strengthen infection surveillance in Japan. Furthermore, demands for the examination and testing of CRE infections have increased in recent years.

The purpose of this study was to develop a PCRbased tool for the easy and efficient detection of carbapenemase genes in Enterobacteriaceae. Multiplex PCR schemes have been previously reported by several research laboratories (10-15), and although interesting, they did not always match the needs of the clinical and public health settings in Japan, where IMP carbapenemase is the most prevalent. Carbapenemases are highly diverse and have significant regional differences across the global. Therefore, a tool needs to be developed for the efficient diagnosis of carbapenemase genes. Here, we developed a multiplex PCR assay to detect carbapenemase genes in a singletube reaction for rapid and efficient screening.

\section{MATERIALS AND METHODS}

Bacterial strains: Six isolates with carbapenemase genes were used to prepare positive control DNA templates, stored at the Antimicrobial Resistance Research Center, National Institute of Infectious
Diseases in Japan; Klebsiella pneumoniae with bla $a_{\mathrm{KPC}-2,}$

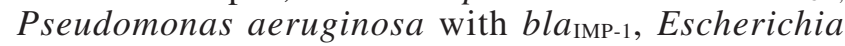
coli with bla $a_{\mathrm{NDM}-1}$, Pseudomonas putida with bla ${ }_{\mathrm{VIM}-2}$, Klebsiella pneumoniae with bla $a_{\mathrm{OXA}-181}$, and Klebsiella pneumoniae with $b l a_{\mathrm{GES}-24}$. To evaluate the multiplex PCR assay, 51 CRE isolates with carbapenemase genes, and 91 non-CPE isolates from clinical specimens were used. These isolates are listed in Table 1 and were selected and used by each co-author from eight regional laboratories in Japan, as follows: Akita, Yokohama city, Toyama, Osaka, Hiroshima, Kagawa, Ehime, and Kumamoto. The subtypes of the carbapenemase genes were determined mainly using PCR and Sanger sequencing with primers annealed near the dual ends of the coding sequences (16-20). The subtyping of the GES-type gene was performed according to previous reports (21). The subtyping of IMP-1-type carbapenemase genes, however, was performed using the primer pair with IMP-1allF: $5^{\prime}$ ATGAGCAAGTTATCTGTATTC-3' and IMP-1allR: 5'CATCAAAACCAAGCAACTAA-3', respectively. The gene types of ESBL and AmpC $\beta$-lactamase were determined according to previous reports $(22,23)$.

Design of primers for PCR: The sequences of genes that encode carbapenemases were downloaded from NCBI databases (24). Target genes were selected from six groups of carbapenem-hydrolyzing $\beta$ -lactamases previously reported in Japan: bla $a_{\mathrm{KPC}}, b_{1} a_{\mathrm{IMP}}$, bla $_{\mathrm{NDM}}, b l a_{\mathrm{VIM}}, b l a_{\mathrm{OXA}-48-l i k e}$, and $b l a_{\mathrm{GES}}(25)$. The genes downloaded were as follows: 24 genes from KPC(1 to 25$), 66$ from IMP-(1 to 75), 15 from NDM-(1 to 15), 37 from VIM-(1 to 39), 21 from OXA-48-like-(48 to 505), and 31 from GES-(1 to 31$)$, respectively. The sequences were aligned using Clustal Omega (26), and highly homologous regions were selected for primer design using BioEdit (http://www.mbio.ncsu.edu/ BioEdit/bioedit.html). The suitability of the primers was confirmed using the OligoEvaluator web service (http:// www.oligoevaluator.com/LoginServlet).

To maximize screening efficiency, group-specific primer pairs for the $b l a_{\mathrm{OXA}-48 \text {-like }}$ and $b l a_{\mathrm{GES}}$ groups were detected in all variants, including non-carbapenemase. Two sets of primer pairs for the detection of several bla $_{\mathrm{IMP}}$ variants were designed to detect the same size of each amplicon. This design strategy, aimed at the detection of many bla $a_{\mathrm{IMP}}$ variants, was comprised of only one mixed base in the primer sequence; an $\mathrm{A} / \mathrm{G}$ or $\mathrm{C}$ / $\mathrm{T}$ type mismatch at one position was allowed. The Tm value was set to $60^{\circ} \mathrm{C}$ or higher.

The in silico evaluation of the designed PCR primers was performed using MFEprimer-3.0 (27).

DNA extraction and multiplex PCR: DNA was prepared by suspending several colonies of each bacterial strain in $100 \mu \mathrm{l}$ of distilled water, boiling at $98^{\circ} \mathrm{C}$ for $10 \mathrm{~min}$, and centrifuging the cell extract for $5 \mathrm{~min}$ at $15,000 \times g$ at $4^{\circ} \mathrm{C}$. The supernatant was used as the template DNA for PCR.

For PCR, the QIAGEN Multiplex PCR Plus Kit was used with $2 \times$ PCR MasterMix (final concentration: $1 \times), 0.2 \mu \mathrm{M}$ of each primer, $2.5 \mu \mathrm{l}$ of Q-Solution, 2.5 $\mu \mathrm{l}$ of CoralLoad Dye, and $1 \mu \mathrm{l}$ of template DNA at a total volume of $25 \mu \mathrm{l}$. Amplification was carried out in a standard PCR thermal cycler as follows: $5 \mathrm{~min}$ at $95^{\circ} \mathrm{C}$ (initial activation step), followed by 25 cycles of 
Table 1. Clinical gram-negative rod-shaped bacteria used in this study

\begin{tabular}{|c|c|c|c|c|c|}
\hline & \multirow{2}{*}{ Bacterial strains } & \multirow{2}{*}{$\begin{array}{c}\text { Type of } \beta \text {-lactamase } \\
\text { gene detected }\end{array}$} & \multirow{2}{*}{$\begin{array}{l}\text { Analysis } \\
\text { method }^{1)}\end{array}$} & \multicolumn{2}{|c|}{ No. of strains tested } \\
\hline & & & & Subtotal & Total \\
\hline \multirow{20}{*}{$\begin{array}{l}\text { Carbapenemase gene } \\
\text {-positive }\end{array}$} & Citrobacter freundii & $b l a_{\mathrm{IMP}-1}$ & 1 & 3 & \multirow{20}{*}{51} \\
\hline & Enterobacter cloacae & $b l a_{\mathrm{NDM}-5}$ & $1(16)$ & 1 & \\
\hline & Enterobacter cloacae & $b l a_{\mathrm{IMP}-1}$ & 1 & 12 & \\
\hline & Enterobacter asburiae & $b l a_{\mathrm{IMP}-1}$ & 1 & 1 & \\
\hline & Escherichia coli & $b l a_{\text {OXA-181 }}$ & 1 & 2 & \\
\hline & Escherichia coli & $b l a_{\mathrm{IMP}-6}$ & $1,2(21)$ & 2 & \\
\hline & Escherichia coli & $b l a_{\mathrm{IMP}-1}$ & 1 & 2 & \\
\hline & Escherichia coli & $b l a_{\mathrm{NDM}-5}$ & 1 (16) & 1 & \\
\hline & Klebsiella oxytoca & $b l a_{\mathrm{IMP}-1}$ & 1 & 8 & \\
\hline & Klebsiella oxytoca & $b l a_{\mathrm{IMP}-10}$ & 1 & 2 & \\
\hline & Klebsiella pneumoniae & $b l a_{\mathrm{IMP}-1}$ & 1 & 4 & \\
\hline & Klebsiella pneumoniae & $b l a_{\mathrm{GES}-24}$ & $1(18)$ & 2 & \\
\hline & Klebsiella pneumoniae & $b l a_{\mathrm{IMP}-11}$ & $1(19)$ & 2 & \\
\hline & Klebsiella pneumoniae & $b l a_{\mathrm{IMP}-6}$ & $1,2(21)$ & 2 & \\
\hline & Klebsiella pneumoniae & $b l a_{\mathrm{GES}-24, \text { blaIMP-11 }}$ & $1(18,19)$ & 1 & \\
\hline & Klebsiella pneumoniae & $b l a_{\mathrm{KPC}-2}$ & $1(20)$ & 2 & \\
\hline & Klebsiella pneumoniae & $b l a_{\mathrm{OXA}-48}$ & $1(17)$ & 1 & \\
\hline & Klebsiella pneumoniae & $b l a_{\mathrm{NDM}-1}, b l a_{\mathrm{OXA}-232}$ & $1(16,17)$ & 1 & \\
\hline & Kluyvera cryocrescens & $b l a_{\mathrm{IMP}-1}$ & 1 & 1 & \\
\hline & Serratia marcescens & $b l a_{\mathrm{GES}-5}$ & $1(18)$ & 1 & \\
\hline \multirow{19}{*}{$\begin{array}{l}\text { Carbapenemase gene } \\
\text {-negative }\end{array}$} & Citrobacter freundii & N.D. ${ }^{3)}$ & 2 & 3 & \multirow{19}{*}{91} \\
\hline & Enterobacter cloacae & N.D. & 2 & 15 & \\
\hline & Enterobacter cloacae & bla $a_{\mathrm{TEM}}, b l a_{\mathrm{CTX}-\mathrm{M}-1 \text {-group }}$ & 2 & 1 & \\
\hline & Enterobacter cloacae & $\mathrm{EBC}_{\text {family }}^{4)}$ & 2 & 10 & \\
\hline & Enterobacter asburiae & EBC family & 2 & 4 & \\
\hline & Escherichia coli & CIT family $^{4)}$ & 2 & 1 & \\
\hline & Escherichia coli & $b l a_{\mathrm{TEM}}, b l a_{\mathrm{CTX}-\mathrm{M}-2 \text {-group }}$ & 2 & 3 & \\
\hline & Escherichia coli & $b l a_{\text {CTX-M-9-group }}$ & 2 & 5 & \\
\hline & Klebsiella aerogenese & N.D. & 2 & 14 & \\
\hline & Klebsiella aerogenes & EBC family & 2 & 13 & \\
\hline & Klebsiella oxytoca & N.D. & 2 & 1 & \\
\hline & Klebsiella pneumoniae & bla $_{\mathrm{SHV}}, b l a_{\mathrm{CTX}-\mathrm{M}-2 \text {-group }}$ & 2 & 4 & \\
\hline & Klebsiella pneumoniae & $b l a_{\mathrm{CTX}-\mathrm{M}-1 \text {-group }}$ & 2 & 2 & \\
\hline & Klebsiella pneumoniae & $b^{b l a} a_{\mathrm{SHV}}$ & 2 & 1 & \\
\hline & Klebsiella pneumoniae & $b l a_{\mathrm{SHV}}, b l a_{\mathrm{CTX}-\mathrm{M}-9 \text {-group }}$ & 2 & 1 & \\
\hline & Klebsiella pneumoniae & N.D. & 2 & 6 & \\
\hline & Proteus mirabilis & bla $_{\mathrm{CTX-M-2-group}}$ & 2 & 2 & \\
\hline & Providencia stuartii & N.D. & 2 & 1 & \\
\hline & Serratia marcescens & N.D. & 2 & 4 & \\
\hline
\end{tabular}

${ }^{1)}$ : Decision methods of carbapenemse gene subtypes: 1, PCR and Sanger sequencing; 2, PCR. Numbers in parenthesis were the reference numbers.

2): including CRE-suspected strains. PCR were performed according to reference 22 and 23.

3): N.D., not detected.

4): Notated according to reference 23 .

${ }^{5}$ : Formerly, Enterobacter aerogenes.

$95^{\circ} \mathrm{C}$ for $30 \mathrm{~s}, 60^{\circ} \mathrm{C}$ for $90 \mathrm{~s}$, and $72^{\circ} \mathrm{C}$ for $60 \mathrm{~s}$. The last extension step was performed at $68^{\circ} \mathrm{C}$ for $10 \mathrm{~min}$. A few aliquots of the PCR products were used for electrophoresis on a 3\% NuSieve 3:1 agarose gel stained with ethidium bromide or GelRed (Biotium, Hayward, CA, USA) to confirm the amplicon DNA (Fig. 1). To assess the robustness of PCR, the standard PCR thermal cyclers used in this study were as follows: ProFrex PCR System, SimpliAmp thermal cycler, Veriti 96-well thermal cycler, GeneAmp PCR System 9700 (Thermo Fisher Scientific, Inc. MA, USA), S1000 thermal cycler (Bio-Rad Laboratories Inc., Tokyo, Japan), and PCR
Thermal Cycler Dice (TaKaRa Bio Inc. Shiga, Japan).

In addition to the QIAGEN Multiplex PCR plus Kit, other PCR enzymes used were as follows: Illustra Hot Start Mix RTG (GE Healthcare UK Ltd, England), puRe Taq Ready-To-Go PCR Beads (GE Healthcare UK Ltd, England), GoTaq Hot Start Green MasterMix (Promega KK, Tokyo, Japan), Multiplex PCR Assay Kit (Takara Bio Inc.), Takara Ex Taq Hot Start Version (Takara Bio Inc.). 


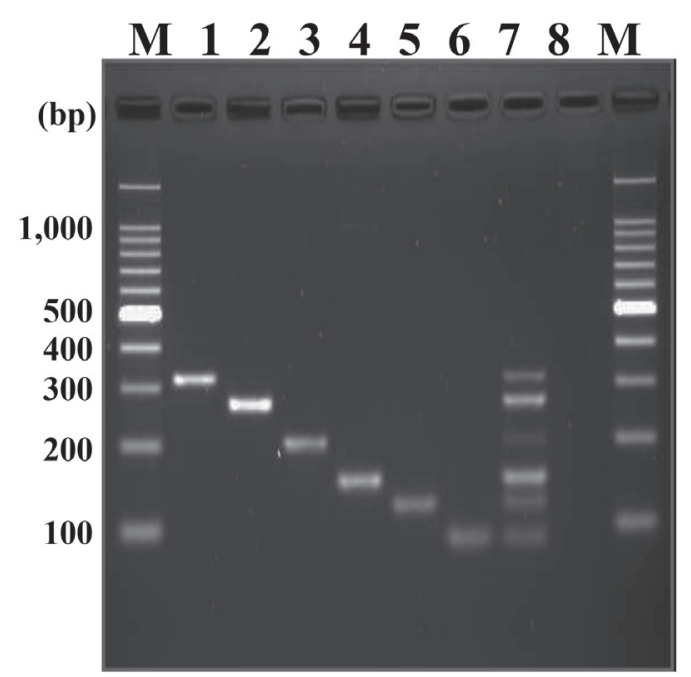

Fig. 1. Detection of PCR products by multiplex PCR for six carbapenemase genes PCR products were separated on a $3 \%$ agarose gel in $1 \times$ TAE buffer. Lane M, 100-bp DNA ladder; lane 1, KPC-type enzyme producing strain; lane 2, IMP-type; lane3, NDM-type; lane 4, VIM-type; lane 5, OXA-48-liketype; lane 6, GES-type; lane 7, PCR products obtained using a mixture of the six template DNA from each carbapenemasepositive strain; lane 8 , PCR product of the negative control (used distilled water instead of template DNA solution). The size in base pairs is shown on the left.
Design of group-specific primers for multiplex PCR in a single-tube assay: A single-tube multiplex PCR assay was designed in this study. All the primer sequences used are listed in Table 2.

The potential of the PCR of all the primers was determined via in silico simulation for all applicable carbapenemase gene sequences. The in silico PCR results were combined with the results of MFEprimer-3.0. The primers paired with stable duplex formation for target sequences (indicated the lower of $\Delta \mathrm{G}$ value) were determined as PCR-positive. At least one of the paired primers without a stable duplex was considered to be PCR-negative. All members of the bla $a_{\mathrm{KPC}}$ and $b l a_{\mathrm{NDM}}$ groups were estimated as detectable. However, some genes of the bla $_{\mathrm{IMP}}, b_{a_{\mathrm{VIM}}}$, and $b l a_{\mathrm{OXA}-48 \text {-like }}$ groups were not detectable. There were nine undetectable genes of carbapenemase as follows: three genes of $b a_{\mathrm{IMP}-31,35}$, and 58,

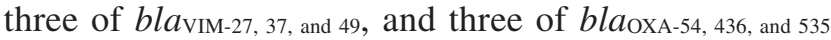
(Table 2). Sixteen genes of IMP-type carbapenemases in Table 2 were estimated to be PCR-positive from the results, with the option of allowing one mismatch of the MFEprimer3.0 command line program. In addition, some genes of the bla $a_{\mathrm{OXA} 48-\text { like }}$ and $b a_{\mathrm{GES}}$ groups without carbapenemase activity were also estimated to be

Table 2. Sequences of primers used for multiplex PCR to detect genes encoding carbapenemases in Enterobacteriaceae, and in silico simulations of PCR performances

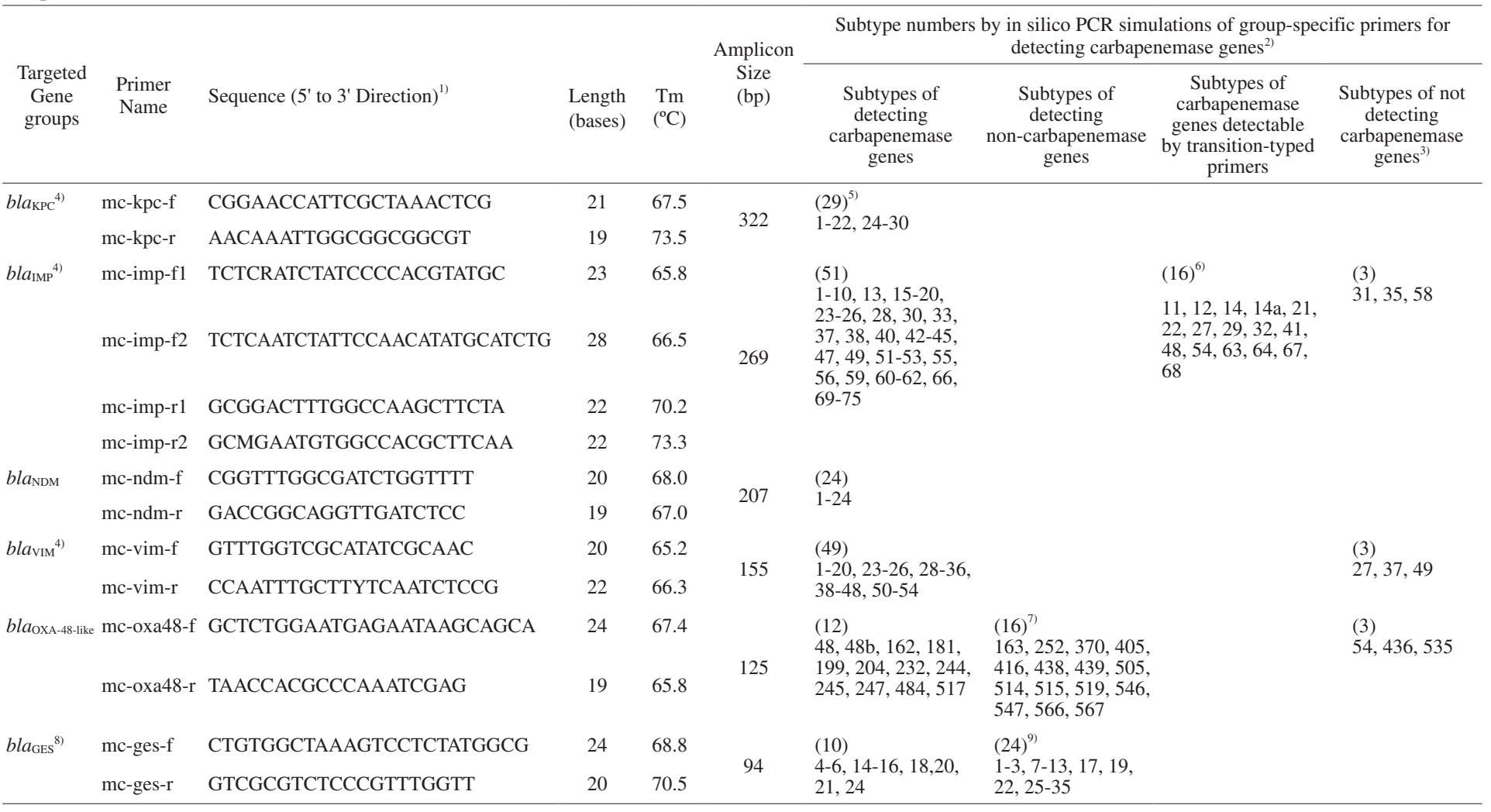

\footnotetext{
${ }^{1)}$ : For degenerate primers: $\mathrm{R}=\mathrm{A}$ or $\mathrm{G} ; \mathrm{Y}=\mathrm{C}$ or $\mathrm{T} ; \mathrm{M}=\mathrm{A}$ or $\mathrm{C}$

2): All designed primers were not tested because of difficulties in preparing all the positive control templates in this study. in silico PCR simulations were calculated using MFEprimer-3.0 (27).

${ }^{3)}$ : Host organisms with these genes are as follows: Pseudomonas spp. for three bla $a_{\mathrm{IMP}-(31.35 \text { and 58) }}$ and three blaviM-(37 and 49), Shewanella spp. for two bla $a_{\mathrm{OXA}-(54 \text { and 535) }}$ as glucose non-fermenters; Klebsiella pneumoniae for bla ${ }_{\mathrm{VIM}-27}$ and Citrobacter freundii for bla $\mathrm{OXX}_{-436}$ as glucose fermenters. These information are obtained from the public data under accession numbers as follows: KF148593, JF816544, KU647281, JX131372, KU663374. AY500137, KX828709, HQ858608 and KT959108, respectively.

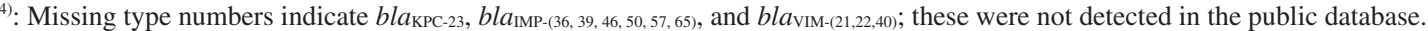

${ }^{5)}$ : Numbers of corresponding $\beta$-lactamase genes in parenthesis.

6): Subtypes that the duplex will probably be amplified if it is a primer with at least one nucleotide mutation by analysis of MFEprimer-3.0. bla PCR-positive in vitro (Figure 2).

7): Two of the $15 \beta$-lactamases are ESBL; bla $a_{\mathrm{OXA}-(163,405) \text {. }}$

${ }^{8)}: b_{\mathrm{GES}-23}$ is undetectable by the PCR primers, which is ESBL.

${ }^{9)}$ : Five of the $24 \beta$-lactamase genes are ESBL; bla $a_{\mathrm{GES}-(1-3,8,11)}$.
} 
(a) $b l a_{\text {IMP-11 }}$
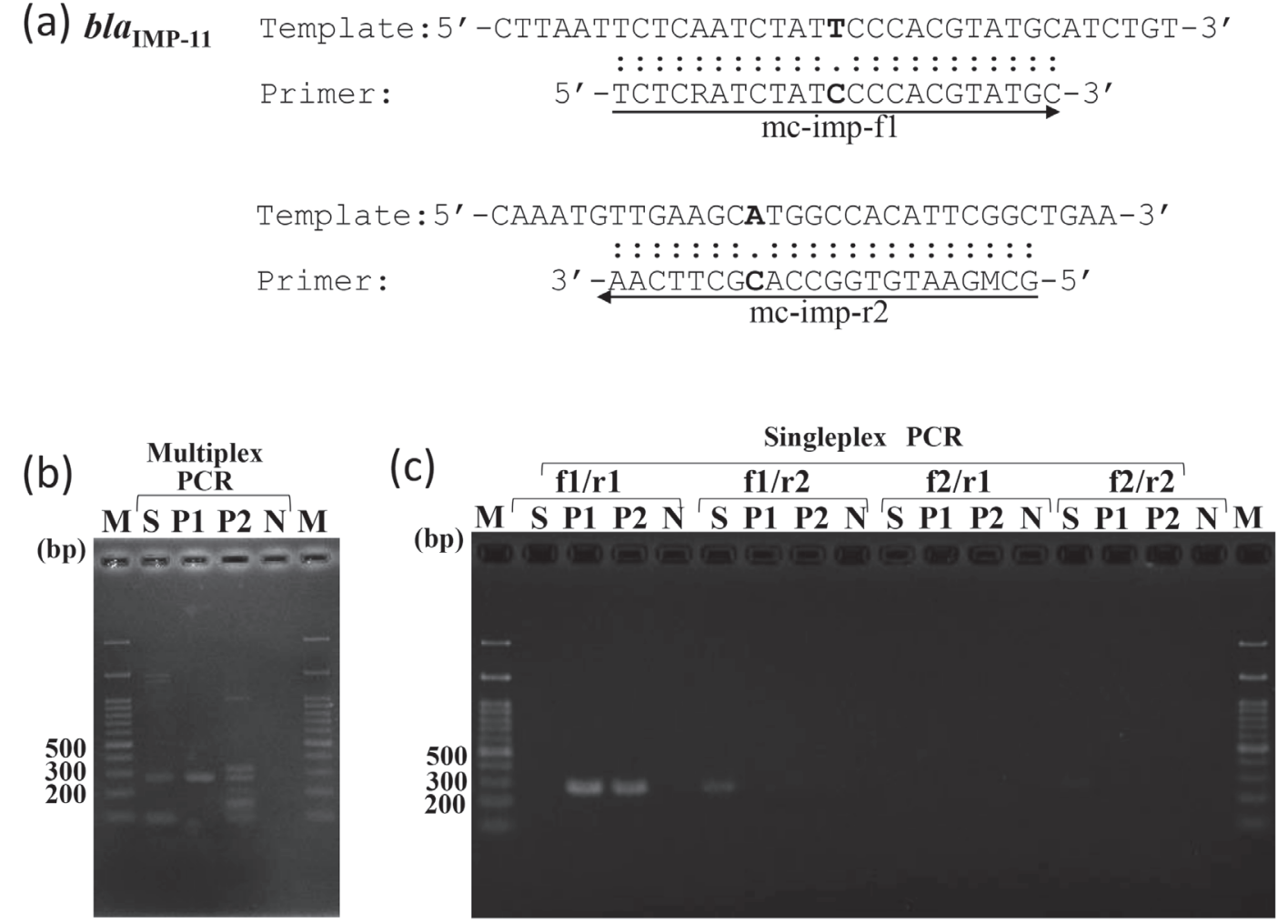

Fig. 2. PCR products by a mismatch primer for detection of a blaIMP variant type by multiplex PCR. (a) Sequence alignments of binding regions with the forward primer, mc-imp-f1, and the reverse primer, mc-imp-r2, for $b l a_{\mathrm{IMP}-11}$. The binding regions show one mismatch base-pairing (bold face) in each primer sequence. (b) PCR products using the template DNA from Klebsiella pneumoniae with $b l a_{\mathrm{IMP}-11}$ and bla $_{\mathrm{GES}-24}$ by multiplex PCR. (c) Singleplex PCR for bla $a_{\mathrm{IMP}-7}$ gene DNA using primers for bla $a_{\mathrm{IMP}}$ of the multiplex PCR. Primer sets used for singleplex PCR are as follows: f1, mc-imp-f1; f2, mc-imp-f2; r1, mc-imp-r1; r2, mc-imp-r2 (Table 2). Lane M, DNA ladder; lane S, the template DNA with $b l a_{\mathrm{IMP}-7}$ gene; lane P1, the template DNA with bla $a_{\mathrm{IMP}-1}$ gene as reference; lane P2, the PCR products obtained using a mixture of six template DNA from each carbapenemase-positive strains; lane N, PCR product of the negative control (distilled water).

detected as follows: 15 bla $a_{\mathrm{OXA}}$-types and 24 bla $a_{\mathrm{GES}}$-types. The primer sequences for the detection of all groups, calculated lengths of corresponding amplicons, and in silico information are also provided in Table 2.

PCR performances using positive DNA templates with carbapenemase genes: The multiplex primer sets were evaluated using DNA extracts from each strain with bla $_{\mathrm{KPC}}$, bla $a_{\mathrm{IMP}}$, bla $_{\mathrm{NDM}}$, bla $a_{\mathrm{VIM}}$, bla $a_{\mathrm{OXA}-48-\mathrm{like}}$, and $b l a_{\mathrm{GES}}$ genes as the positive controls. Under optimized conditions of PCR using the QIAGEN Multiplex PCR Plus Kit, the mixed primers yielded amplified products of the expected size, and the same size detected when using individual primers for the six groups (Fig. 1) using six standard PCR thermal cyclers. Small amounts of non-specific amplified products were detected. Setting the annealing temperature to $60^{\circ} \mathrm{C}$ was critical to obtain accurate results.

Evaluation of the primer mixture for multiplex PCR in a single tube using clinical CRE isolates: To confirm the PCR performance of the multiplex PCR primers, template DNA extracted from 51 clinical isolates of six genera previously identified as CRE with carbapenemase genes, and 91 clinical isolates of seven genera without carbapenemase genes (Table 1), were used. PCR was performed at eight laboratories using several thermal cyclers. Non-specific amplified products were observed in part using the DNA of the CRE strains with the carbapenemase gene (e.g. a 1000-bp PCR product in lane P2 of Fig. 2b). However, when compared with the amplified products using positive controls, their sizes were always different, and the amount of amplification was low.

Further, with PCR using the template DNA of CRE strains without the carbapenemase genes, the amplified product expected as carbapenemase gene was not detected. From the above results, it was possible to determine whether the amplified product of the expected size targeting the carbapenemase gene could be obtained, even when a non-specific amplified product was detected. As a result, it was confirmed that the combination of the QIAGEN Multiplex PCR Plus Kit and our multiplex primer sets had the best performance. The assay had an overall sensitivity and specificity of $100 \%$.

In addition, commercially available kits or enzymes other than the QIAGEN Multiplex PCR Plus Kit were used to perform and test the PCR assay. Depending on the kit, specific or non-specific amplified products were detected. Using puRe Taq Ready-to-Go PCR Beads, GoTaq Hot Start Green MasterMix, and Ex Taq HS, small amounts of non-specific amplification products were detected, whereas non-specific amplification was 
observed using the Multiplex PCR Assay Kit.

Evaluation of PCR products using a mismatch primer for the detection of a $b \boldsymbol{b a}_{\mathrm{IMP}}$ variant type in multiplex PCR: In the multiplex primer mixture for detecting $b l a_{\mathrm{IMP}}$, several $b l a_{\mathrm{IMP}}$ variants were expected to be detected using MFEprimer-3.0 (27). In this study, 16 out of 70 bla $_{\mathrm{IMP}}$ genes were expected to be amplified in silico, with at least one primer having a mismatched primer. In this study, the IMP types used for evaluating the PCR assay were IMP-1, 6, 10, and 11 for the CPE strains (Table 1). Among them, the IMP-11 type was presumed to be PCR-positive using the primer set with each transition-type mismatch base using MFEprimer-3.0 (Fig. 2a). In multiplex PCR using the template DNA from the Klebsiella pneumoniae strain with $b l a_{\mathrm{IMP}-11}$ and $b l a_{\mathrm{GES}-24}$ (Table 1), both carbapenemase genes were PCR-positive (Fig. 2b). Four singleplex PCR assays used a combination of two forward primers, and two reverse primers were then performed to confirm the actual primer pairs in this PCR. The PCR product was only detected using the primer pair of mc-imp-f1 and mc-imp-r2 (Fig. 2c). This demonstrated that one of the four sets of PCR primers for the bla $a_{\mathrm{IMP}}$-group functioned as a specific amplification one-transition-type mismatch mode.

\section{DISCUSSION}

In addition to carbapenems, CPE often acquires resistance to other antimicrobials used in clinical settings (26) and are difficult to treat if infectious diseases are caused. It is, therefore, necessary to be vigilant about infection when resistance genes are transformed with a plasmid into a bacterial species and then propagated. The first laboratory examinations included "MIC value of the assigned antibiotic" or "the inhibition zone diameter of disk" in Enterobacteriaceae isolates. However, some CPEs showed susceptibility to certain carbapenem antibiotics (5). Therefore, it is difficult to distinguish CPE by phenotypic examination using conventional antimicrobial susceptibility tests alone. Several methods for detecting CPE have been reported. The method for detecting carbapenemase by immunochromatography is quick (15 min).

Moreover, although the disc method and selective agar medium of the CRE screening method for the detection of carbapenemase are commercially available, they require around 18-24 h to determine the result, based on the culture time of the bacteria. Although these methods are already commercially available and easy to use, some detection performances for determining CPE are insufficient (29). Meanwhile, the detection of the carbapenemase gene is considered a reliable detection method. In addition, the rapid and accurate detection of foreign CRE is required to prevent nosocomial infections. These tests detect carbapenemase genes and require molecular epidemiological information. Therefore, the multiplex PCR method is the best screening tool, as it can rapidly determine multiple genotypes. For example, the method of Poirel et al. (11) targeted several carbapenemase genes; however, this reaction required three tubes and may require further optimization for use in Japan.

In contrast, the method of Sakanashi et al. (14) is suitable for use in the laboratories of medical facilities since it is a one-tube reaction and targets the carbapenemase genes specific to Japan. However, for this method, the primers need to be prepared in-house. Since a specific enzyme and PCR thermal cycler are required, optimization may be necessary. The Cica Geneus ${ }^{\circledR}$ Carbapenemase Genotype Detection KIT 2 (Kanto Chemical Co., Inc.) is a commercially available product that not only targets the six major carbapenemase genes detected in Japan but can also detect carbapenemasetype GES genes. However, this assay is performed in a two-tube reaction, which is expensive. Therefore, our single-tube PCR method seems to be superior in terms of both operationality and cost. Furthermore, it is important to deal with the emergence of new CRE subtypes, as well as new carbapenemase genes. The PCR assay presented here will maintain its performance in the public health research community in Japan.

In the multiplex PCR assay, the Tm values of all the primer sequences were designed to be $60^{\circ} \mathrm{C}$ or higher to maintain their specificity. Therefore, setting the annealing temperature to $60^{\circ} \mathrm{C}$ was critical to obtain accurate results in actual PCR. A major feature of the multiplex PCR method is the primers used for detecting IMP-type carbapenemases. Since there are multiple genotypes for the IMP type, a primer that allows for transition-type mismatch was designed to detect the IMP type. The primers with transition-type mismatch were expected to function as PCR primers despite a mismatch, as there is no change in the purine or pyrimidine bases. The primers designed in this study were subjected to PCR quality control using MFEprimer-3.0 (27). This software analyzes the specific reaction of primer and its target DNA duplex formation by searching for thermodynamic stability using the k-mer algorithm on the template DNAs. The number of $b a_{\mathrm{IMP}}$ detectable by the program as transition-typed primers was 16 (Table 2 ). The $b l a_{\mathrm{IMP}}$ types used for evaluating the PCR method were IMP-1, 6, 10, and 11 for the CPE strains (Table 1). Among them, bla $a_{\mathrm{IMP}-11}$ was PCR-positive with both a mismatch and a primer pair (Fig. 2a). The results suggest that PCR with one transition-type mismatched primer has a functioning specificity (Fig. 2).

Non-detectable carbapenemase genes were evaluated in silico, including three genes of $b l a_{\mathrm{IMP}}$, three genes of bla $a_{\mathrm{VIM}}$, and three genes of bla $a_{\text {OXA48-like }}$ groups (Table 2). Among these nine genes, the host organisms with seven genes were glucose non-fermentative bacteria (e.g., Pseudomonas or Shewanella spp.), which did not belong to Enterobacteriaceae (Footnote c in Table 2). Therefore, it is not believed that these results reduce the value of our multiplex PCR assay for CRE testing in this study.

In the PCR-positive cases of the $b l a_{\mathrm{OXA}-48-\text {-like }}$ and $b l a_{\mathrm{GES}}$ groups, the selection of the CPE isolate is not possible due to the inability to distinguish carbapenemase from ESBL and/or others. Among the 15 subtypes of the bla $a_{\text {OXA48-like }}$ group with carbapenemase activity, 12 subtypes were detectable in silico; however, 16 without carbapenemase activity were also detected. In the $b l a_{\mathrm{GES}}$ group, among 34 detectable subtypes, ten subtypes had carbapenemase activity. Therefore, DNA sequencing following PCR amplification using other primer sets is needed to confirm the carbapenemase-type for 
bla $a_{\text {OXA-48-like }}$ (17) and $b l a_{\text {GES. Alternatively, a PCR assay }}$ for the identification of carbapenemase-type bla $a_{\mathrm{GES}}$ may be useful (30).

In conclusion, the multiplex PCR primers tested in silico and in vitro may be useful for the rapid and efficient screening of the carbapenemase genes of Enterobacteriaceae in both clinical and public health settings. This PCR assay will compensate for the shortfall of phenotypic testing, e.g., drug susceptibility testing and modified carbapenem inactivation method (31). The rapid and accurate diagnosis of CPE will contribute to future attempts at controlling and managing CRE infections.

Acknowledgments This study was financially supported by a Grant-in-Aid from the Japan Agency for Medical Research and Development (AMED), grant number JP18fk0108061.

Conflict of interest None to declare.

\section{REFERENCES}

1. Brenner DJ. Enterobacteriaceae. In: Garrity G, et al, editors. Bergey's manual of systematic bacteriology (Volume1). New York: Springer; 1984. p. 408-516.

2. Nordmann P, Naas T, Poirel L. Global spread of carbapenemaseproducing Enterobacteriaceae. Emerg Infect Dis. 2011;17:1791-8.

3. Lutgringa JD, Limbagob BM. The problem of carbapenemaseproducing-carbapenem-resistant-Enterobacteriaceae detection. J Clin Microbiol. 2016;54:529-34.

4. Ambler RP. The structure of $\beta$-lactamase. Philos Trans R Soc Lond, B Biol Sci. 1980;289:321-31.

5. Poirel L, Potron A, Nordmann P. OXA-48-like carbapenemases: the phantom menace. J Antimicrob Chemother. 2012:67:1597-606.

6. Martínez-Martínez L, Pascual A, Hernández-Allés S, et al. Roles of $\beta$-lactamases and porins in activities of carbapenems and cephalosporins against Klebsiella pneumoniae. Antimicrob Agents Chemother. 1999;43:1669-73.

7. Martínez-Martínez L, Conejo M C, Pascual A, et al. Activities of imipenem and cephalosporins against clonally related strains of Escherichia coli hyperproducing chromosomal $\beta$-lactamase and showing altered porin profiles. Antimicrob Agents Chemother. 2000;44:2534-6.

8. De Champs C, Henquell C, Guelon D, et al. Clinical and bacteriological study of nosocomial infections due to Enterobacter aerogenes resistant to imipenem. J Clin Microbiol. 1993;31:123-7.

9. Jalaluddin S, Devaster JM, Scheen R, et al. Molecular epidemiological study of nosocomial Enterobacter aerogenes isolates in a Belgian hospital. J Clin Microbiol. 1998;36:1846-52.

10. Dallenne C, Da Costa A, Decre' D, et al. Development of a set of multiplex PCR assays for the detection of genes encoding important $\beta$-lactamases in Enterobacteriaceae. J Antimicrob Chemother. 2010;65:490-5.

11. Poirel L, Walsh TR, Cuvillier V, et al. Multiplex PCR for detection of acquired carbapenemase genes. Diagn Microbiol Infect Dis. 2011;70:119-23.

12. Monteiro J, Widen RH, Pignatari ACC, et al. Rapid detection of carbapenemase genes by multiplex real-time PCR. J Antimicrob Chemother. 2012;67:906-9.

13. van der Zee A, Roorda L, Bosman G. Multi-centre evaluation of real-time multiplex PCR for detection of carbapenemase genes OXA-48, VIM, IMP, NDM, and KPC. BMC Infect Dis. 2014;14:27.

14. Sakanashi D, Miyazaki N, Suzuki T, et al. Screening multiplex PCR for six important plasmid-mediated carbapenemase genes. Jpn J Med Technol. 2015;64:460-7 (Japanese)

15. Kaase M, Szabados F, Wassill L, et al. Detection of carbapenemases in Enterobacteriaceae by a commercial multiplex PCR. 2012;50: 3115-8.

16. Nordmann P, Boulanger AE, Poirel L. NDM-4 Metallo- $\beta$-lactamase with increased carbapenemase activity from Escherichia coli. Antimicrob Agents Chemother. 2012;56:2184-6.

17. Poirel L, Héritier C, Tolün V, et al. Emergence of oxacillinasemediated resistance to imipenem in Klebsiella pneumoniae. Antimicrob Agents Chemother. 2004;48:15-22.

18. Wachino J, Doi Y, Yamane K, et al. Nosocomial spread of ceftazidime-resistant Klebsiella pneumoniae strains producing a novel class A $\beta$-lactamase, GES-3, in a neonatal intensive care unit in Japan. Antimicrob Agents Chemother. 2004;48:1960-7.

19. Notake S, Matsuda M, Tamai K, et al. Detection of IMP metallo$\beta$-lactamase in carbapenem-nonsusceptible Enterobacteriaceae and non-glucose-fermenting Gram-negative rods by immunochromatography assay. J Clin Microbiol. 2013;51:1762-8.

20. Cuzon G, Naas T, Truong H, et al. Worldwide diversity of Klebsiella pneumoniae that produce $\beta$-lactamase bla $_{\mathrm{KPC}-2}$ gene. Emerg Infect Dis. 2010;S16:1349-56.

21. Kayama S, Shigemoto N, Kuwahara R, et al. Rapid detection of blaIMP-6 by amplification refractory mutation system. J Microbiol Methods. 2012;88:182-4.

22. Le QP, Ueda S, Nguyen TNH, et al. Characteristics of extendedspectrum $\beta$-lactamase-producing Escherichia coli in retail meats and shrimp at a local market in Vietnam. Foodborne Pathog Dis. 2015;12:719-25.

23. Pérez-Pérez FJ, Hanson ND. Detection of plasmid-mediated ampC $\beta$-lactamase genes in clinical isolates by using multiplex PCR. J Clin Microbiol. 2002;40:2153-62.

24. NCBI database, National Center for Biotechnology Information. Available at <https://www.ncbi.nlm.nih.gov/>. Accessed December 20, 2018.

25. National Institute of Infectious Diseases and Tuberculosis and Infectious Diseases Control Division, Ministry of Health, Labour and Welfare. Mechanism of carbapenem resistance among Enterobacteriaceae-characteristics and trends. Infect Agents Surveillance Rep. 2014;35:283-4.

26. Sievers F, Wilm A, Dineen D, et al. Fast, scalable generation of high-quality protein multiple sequence alignments using Clustal Omega. Mol Syst Biol 2011;7:539.

27. Wang K, Li H, Xu Y, et al. MFEprimer-3.0: quality control for PCR primers. Nucleic Acids Res. 2019;47:W610-3.

28. Hirsch EB, Tam VH. Detection and treatment options for Klebsiella pneumoniae carbapenemases (KPCs): an emerging cause of multidrug-resistant infection. J Antimicrob Chemother. 2010;65:1119-25

29. National Institute of Infectious Diseases and Tuberculosis and Infectious Diseases Control Division, Ministry of Health, Labour and Welfare. Microbiological testing methods for carbapenemaseproducing Enterobacteriaceae in hospital settings. Infect Agents Surveillance Rep. 2019;40:22-4

30. Kayama S, Yano R, Yamasaki K, et al. Rapid identification of carbapenemase-type $b l a_{\mathrm{GES}}$ and ESBL-type $b$ la $_{\mathrm{GES}}$ using multiplex PCR. J Microbiol Methods. 2018;148:117-9.

31. Pierce VM, Simner PJ, Lonsway DR, et al. The modified carbapenem inactivation method (mCIM) for phenotypic detection of carbapenemase production among Enterobacteriaceae. J Clin Microbiol. 2017:55:2321-33. 